\title{
Undescended ovary without abnormal development of uterus and urinary system: a report of four cases
}

Weixia Wei ${ }^{1,2+}$, Wenji Luo ${ }^{1,2 \dagger}$, Qicai Hu ${ }^{1,2}$, Liping Zeng ${ }^{1,2}$ and Ruifang $\mathrm{Wu}^{1,2^{*}}$

\begin{abstract}
Background: Congenital anatomic abnormalities of fallopian tubes and ovaries are rarely reported. Herein, we describe four cases of undescended ovary during laparoscopic surgery with abnormal anatomy of fallopian tube, yet without abnormal uterine development and urinary system abnormalities, which are analyzed by their clinical features and effects on reproductive function.

Case presentation: For the patients with undescended ovary, the location of unilateral or bilateral upper poles of the ovaries were usually much higher than that of the bifurcation of the common iliac vessel, and the fallopian tubes at the same side opened in the para-colonic sulcus. Among these four patients, two patients had primary infertility, one patient had tubal pregnancy rupture and bleeding, and one patient had uterine leiomyoma. The development of uterus was normal in all cases, and there was no abnormal development of urinary system. During the infertility examination, the fact that fallopian tubes lifted up in hysterosalpingography (HSG) might be regarded as an indicator of possible undescended ovary. The pelvic ultrasonography examination was of limited use in diagnosing undescended ovary.
\end{abstract}

Conclusion: Laparoscopy is the gold standard for the diagnosis of undescended ovary. When there is periodic postsacral spinal pain, MRI or HSG can be used for diagnosis of undescended ovary.

Keywords: undescended; maldescent; ovary; infertility

\section{Introduction}

Since the congenital abnormalities of fallopian tube and ovary are rarely reported, the definition of undescended ovary has not been well established. Currently, two standards are commonly used to identify the abnormal position of the ovary [1]. First, the ovary extends upward into the abdominal cavity, or the upper pole of ovary extends beyond the incisal edge of the pelvic entrance or above the bifurcation of the common iliac vessels, or

\footnotetext{
*Correspondence: wurfpush@126.com

†Weixia Wei and Wenji Luo contributed equally to this work.

${ }^{2}$ Shenzhen Key Laboratory on Technology for Early Diagnosis of Major

Gynecologic Diseases, Shenzhen ,518036, China

Full list of author information is available at the end of the article
}

even located in the intracolonic sulcus. Second, the ovary with the concomitant fallopian tube also lifts and opens in the normal position. The inherent ligaments are usually longer, while the pelvic ligaments are shorter. The ovary with these futures can be considered as undescended ovary [1-3].

Typically, undescended ovary with an incidence of $0.3 \%$ can be classified into two main categories: one is associated with congenital uterine anomaly, while the other one is not associated with congenital uterine anomaly (isolated) [4, 5]. Undescended ovary and fallopian tubes are more often associated with uterine abnormalities. Among them, up to $20 \%$ and $40 \%$ of patients have Müllerian agenesis and unicorn uterus, respectively [2]. Therefore, the pathogenesis of undescended ovary may be original author(s) and the source, provide a link to the Creative Commons licence, and indicate if changes were made. The images or other third party material in this article are included in the article's Creative Commons licence, unless indicated otherwise in a credit line to the material. If material is not included in the article's Creative Commons licence and your intended use is not permitted by statutory regulation or exceeds the permitted use, you will need to obtain permission directly from the copyright holder. To view a copy of this licence, visit http://creativecommons.org/licenses/by/4.0/. The Creative Commons Public Domain Dedication waiver (http://creativeco mmons.org/publicdomain/zero/1.0/) applies to the data made available in this article, unless otherwise stated in a credit line to the data. 
caused by partial obstruction of the genitourinary crest during the embryonic period.

Isolated congenital anatomic abnormalities of fallopian tubes and ovaries are very rare, and there are only few reports of undescended ovaries and fallopian tubes. Herein, four cases of undescended ovaries found during laparoscopic surgery with abnormal anatomy of fallopian tubes, but without abnormal uterine development and urinary system abnormalities, were reported here. Their clinical features and their effects on reproductive function were analyzed.

\section{Case presentation}

\section{Case 1: Bilateral undescended ovaries}

A 21-year-old woman presented with 3 years of primary infertility (Height: $162 \mathrm{~cm}$; body weight: $64 \mathrm{~kg}$; body mass index (BMI): $24.4 \mathrm{~kg} / \mathrm{m}^{2}$; Chromosome: 46 ther $\mathrm{XX}$ ). Normal female chromosomes were showed in Karyotype analysis. The menstrual cycle was 30-90 days and the menstrual period was 3-5 days. No abnormality was found in basic sex hormones (AMH:11.25 ng/ml). The results of ultrasonography (Figure 1) showed that the size of the uterus was about $40 \times 32 \times 25 \mathrm{~mm}$, the left ovary was unclear, the size of the right ovary was about $19.8 \times$ $10.5 \mathrm{~mm}$, and the structure was solid. Besides, no obvious follicular echo was found. The results of three-dimensional hysterosalpingo-contrast sonography exhibited a bilateral distal tubal obstruction. Laparoscopy and hysteroscopy were performed on July 4, 2016, and the results were shown in Figure 2. Laparoscopy analysis showed that the size of uterus was $4 \times 3 \times 2.5 \mathrm{~cm}$, and its surface was smooth. The bilateral ovaries presented the long and narrow shape. The upper pole of the ovary with a size of $10 \times 3 \times 2.5 \mathrm{~cm}$ bifurcated beyond the common iliac vessels, and extended to the ipsilateral intracolonic sulcus. The cortex was thick. No ovulation spot was found. The length of the bilateral fallopian tubes with the extended ipsilateral ovary was about $18 \mathrm{~cm}$, and endings of the fimbriae extended over the para-colonic sulcus. The proper ovarian ligaments bilaterally lengthened about $5 \mathrm{~cm}$, and the ovarian suspensory ligament shortened about $1 \mathrm{~cm}$. Methylene blue in the fimbria of bilateral fallopian tubes successfully overflowed after methylene blue was injected into the uterine cavity through the uterine catheter. The course of bilateral ureters and the development of uterine cavity under hysteroscopy were normal.

After laparoscopic surgery, the patient prepared for natural childbirth for one year, but she wasn't conceived. Then, we recommended that the patient get an in vitro fertilization and embryo transfer (IVF/ET) treatment, however, the patient did not get treatment due to the financial concerns.

\section{Case 2: Undescended right ovary}

A 34-years-old woman presented with primary infertility for one year. (Height: $163 \mathrm{~cm}$; Body weight: $53 \mathrm{~kg}$; BMI: $19.95 \mathrm{~kg} / \mathrm{m}^{2}$; Menstrual cycle: 30-60 days; Menstrual period 5-6 days; Menstrual volume was normal). Sex hormones were in a normal range. Figure 3 showed results of ultrasonography. We can found that left ovary had a $\mathrm{PCO}$ (polycystic ovary)change and the right ovary was unclear. The hysterosalpingography showed that the

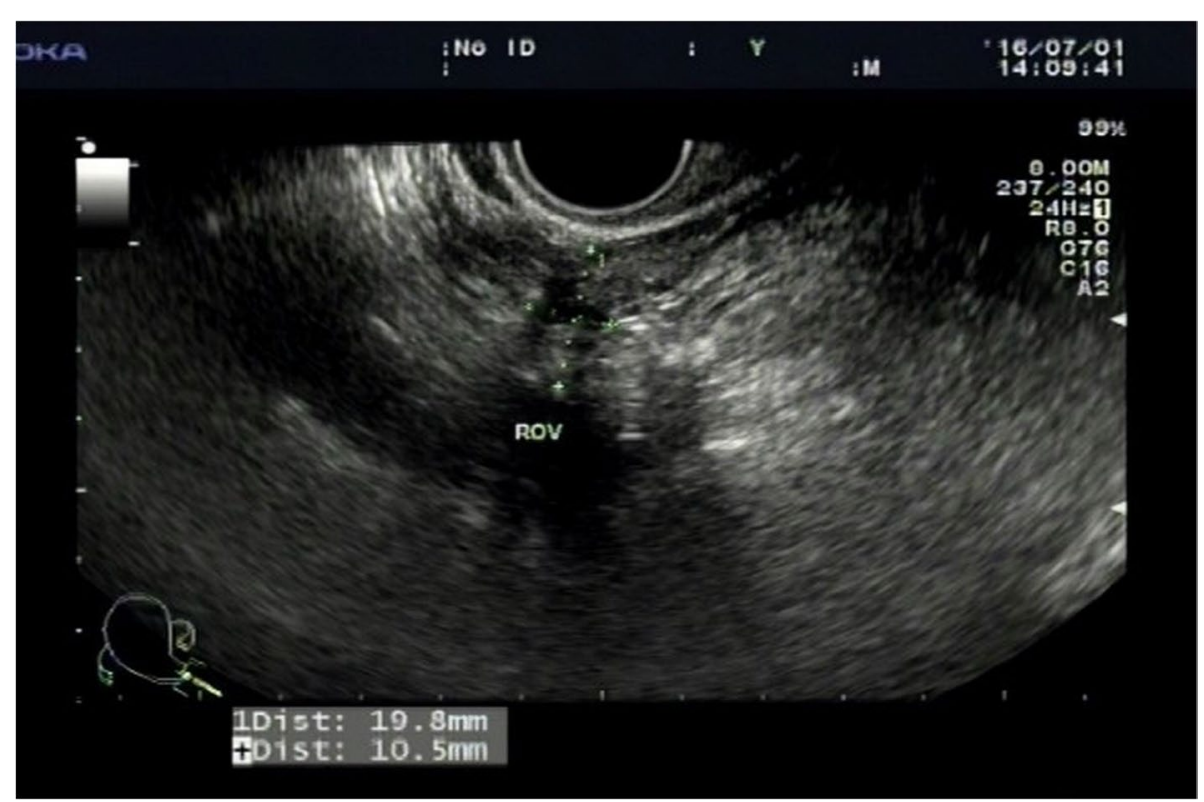

Fig. 1 The transvaginal ultrasound image of Case 1: The size of the right ovary was about $19.8 \times 10.5 \mathrm{~mm}$, the structure was solid 




Fig. 2 Exploratory laparoscopy of Case 1: Exploratory laparoscopy showed that the bilateral undescended ovaries with bilateral fallopian tubes were too long, and the shape of the uterine cavity was normal



Fig. 3 The transvaginal ultrasound image of Case 2:Transvaginal ultrasound image showed PCO (polycystic ovary)changed in the left ovary, and the right ovary was unclear

appearance of the uterus was normal and the bilateral fallopian tubes extended to the level of the third lumbar vertebra. Tubal patency was judged by displaying opaque fluid adjacent to the colon. The left fallopian tube was blocked, while the right fallopian tube was lifted and unobstructed (Figure 4). Hysteroscopy was performed on January 4, 2018, and the result showed uterus with a smooth had a normal size. The right ovary was long and oval. 


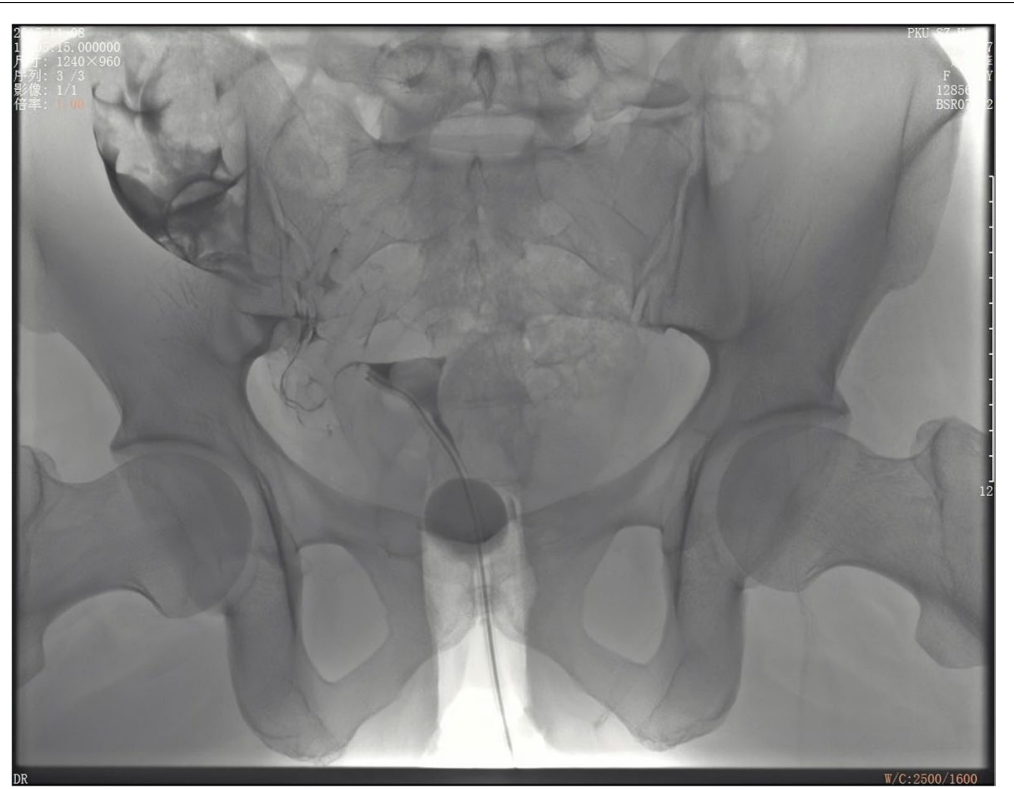

Fig. 4 Salpingography result of Case 2: Salpingography showed that the right fallopian tube was raised and unobstructed, and the left proximal fallopian tube was blocked

The inferior pole of the ovary was in the bifurcation of the common iliac vessels, while the upper pole was in the right interintestinal sulcus of the lateral node after crossing the bifurcation of common iliac arteries (a thick cortex: 6 $\times 4 \times 3 \mathrm{~cm}$ ) without enlarged ovaries. The length of the right fallopian tube was about $18 \mathrm{~cm}$, accompanying with the ipsilateral ovary, and the fimbrial end opened in the right intracolonic sulcus. The proper ovarian ligament on the right side was lengthened about $6 \mathrm{~cm}$, and the ovarian suspensory ligament was shortened about $1 \mathrm{~cm}$. The position of the left ovary was normal $(5 \times 4 \times 3 \mathrm{~cm})$, and the thickened cortex was white. No ovulation was found. The length and shape of the left fallopian tube were normal. Scattered pelvic endometriosis lesions were found in the pelvis. When methylene blue was injected into the uterine catheter, it was noted that the fimbrial end of both fallopian tubes spilled smoothly. Hysteroscopy showed that the development of uterine cavity was normal.

The patient was conceived naturally without treatment. The pregnancy, parturition and baby are normal.

\section{Case 3: Bilateral undescended ovaries with right tubal ectopic pregnancy}

A 28-year-old parturient woman who had a cesarean section, was admitted to the emergency room due to 38 days of amenorrhoea, 4 days of vaginal bleeding, 1 day of lower abdominal pain, and sudden syncope. The result of urine HCG test was positive. The result of complete gynecological examination showed an anteverted uterus with a normal size. Transvaginal ultrasound image showed a normal uterus and uniformly thickened endometrium $(13 \mathrm{~mm})$, and no intrauterine and extrauterine pregnancy were found. Pelvic and abdominal effusion (maximum anterior and posterior diameter $66 \mathrm{~mm}$ ). Bilateral fallopian tubes and ovaries were not found in ultrasonography image. The patient was diagnosed with ectopic pregnancy. Laparoscopic analysis found a normal uterus and undescended ovaries. The length of bilateral fallopian tubes were $18 \mathrm{~cm}$ to $20 \mathrm{~cm}$, which were longer than that of normal fallopian tubes (about $10 \mathrm{~cm}$ ). The superior poles of the both ovaries extended beyond the bifurcation of the common iliac arteries to the ipsilateral intracolonic sulcus. The both fallopian tubes were associated by the lengthening of the ipsilateral ovary, and the fimbrial end opened in the paracolonic sulcus. The ampulla of the right fallopian tube was enlarged by $3 \mathrm{~cm}$, with blood clot attached and active bleeding at its fimbrial end. There were about $1500 \mathrm{ml}$ pelvic hemorrhage and blood clots.

The patient was conceived naturally without treatment. The pregnancy, parturition and baby are normal.

\section{Case 4: left-sided undescended ovary}

A 32-year-old woman (virgin) underwent laparoscopic myomectomy to remove uterine fibroids in July 2019. The patient had no menstrual changes, and her basic sex hormones were normal. During the surgery, the size of posterior intramural fibroids was found to be $9 \diamond 8 \diamond 7$ $\mathrm{cm}$. The left side of ovary had a thin oval shaped structure. The upper pole of the left ovary was located above 
the bifurcation of the total iliac arteries $(8.5 \diamond 4 \diamond 2.5 \mathrm{~cm})$. (Figure 5)

The cortex was thick, and ovulation spotting was observed. The length of left fallopian tube was about $20 \mathrm{~cm}$, accompanied by the ipsilateral ovary, and the fimbrial end opened in the left intracolonic sulcus. The proper ligament of the left ovary was lengthened about 3 $\mathrm{cm}$, and the ovarian suspensory ligament was shortened about $1 \mathrm{~cm}$. The position and shape of the right ovary and fallopian tube were normal (Figure 5). The patient had no plan for pregnancy and did not receive any other treatment.

\section{Discussion}

Previous studies have found that the incidence of undescended ovary was $0.3-0.5 \%$ in the general population [1]. Undescended ovary was found to be associated with uterine anomalies. Women with uterine dysplasia or hypoplasia have the highest incidence of abnormal ovarian position which accounts for $13 \%$ of all uterine abnormalities. This incidence is comparable to an incidence of $17 \%$ reported by Allen et al. using the MRI criterion of the upper pole of ovary placed at or above the level of common iliac arteries [4]. Therefore, it is believed that the ovary identified by MRI as located at or higher than the bifurcation of iliac arteries can be used in the diagnosis of undescended ovary. If hysterosalpingography shows that the fallopian tube is elongated and raised, or pelvic ultrasound cannot locate the ovary in the normal position on both sides of the uterus, undescended ovary can be identified. If the upper poles of ovaries found by MRI of the abdomen and pelvis are located at or higher than the level of common iliac arteries, these will also be the indications of undescended ovary [2]. However, laparoscopic analysis is still the predominant method of diagnosis of undescended ovary by now.
Undescended ovary is often discovered in laparoscopic exploration during the examinations of infertility, uterine dysplasia, epigastric pain, or pregnancy [2]. Our first case of undescended ovary had been incidentally identified in 2016 during a routine laparoscopy procedure of infertility. Of our 4 reported cases, 2 cases were identified during examination of infertility; 1 case was discovered during exploration of ectopic pregnancy; and the last case was accidentally found by laparoscopic myomectomy (Table 1).

Since the actual position of the ovaries is higher than that of the normal pelvic cavity, and if the ultrasound probe does not go further beyond the pelvic cavity to the upper abdomen to explore the ovaries, ultrasound imaging usually fails to detect or only to detect part of the ovaries [6-9]. Therefore, we believe that the pelvic ultrasonography examination is limited use in diagnosing undescended ovary. The position of normal pelvic ovary may not be detected or only partially be detected during ultrasound examination. In two of our cases, preoperative pelvic ultrasonography showed unclear, or in one or both sides of "atrophic small ovaries". Considering the history of infertility, it might be identified as congenital ovarian hypoplasia, yet it was not consistent with the biochemical examination of ovarian function because the basic sex hormones were normal. In Case 3, the ovaries and fallopian tubes were not observed due to a large amount of fluid in the pelvic cavity, which misled the doctor to ignore the possibility of ectopic pregnancy. In addition, three-dimensional hysterosalpingo-contrast sonography of infertility may also lead to a false positive result. In Case 1, since the ultrasound probe was unable to extend to the iliac fossa to examine ectopic fallopian tubes and ovaries, it was impossible to detect the overflow of the contrast agent from the fallopian tube, and there was strong halo of the contrast agent

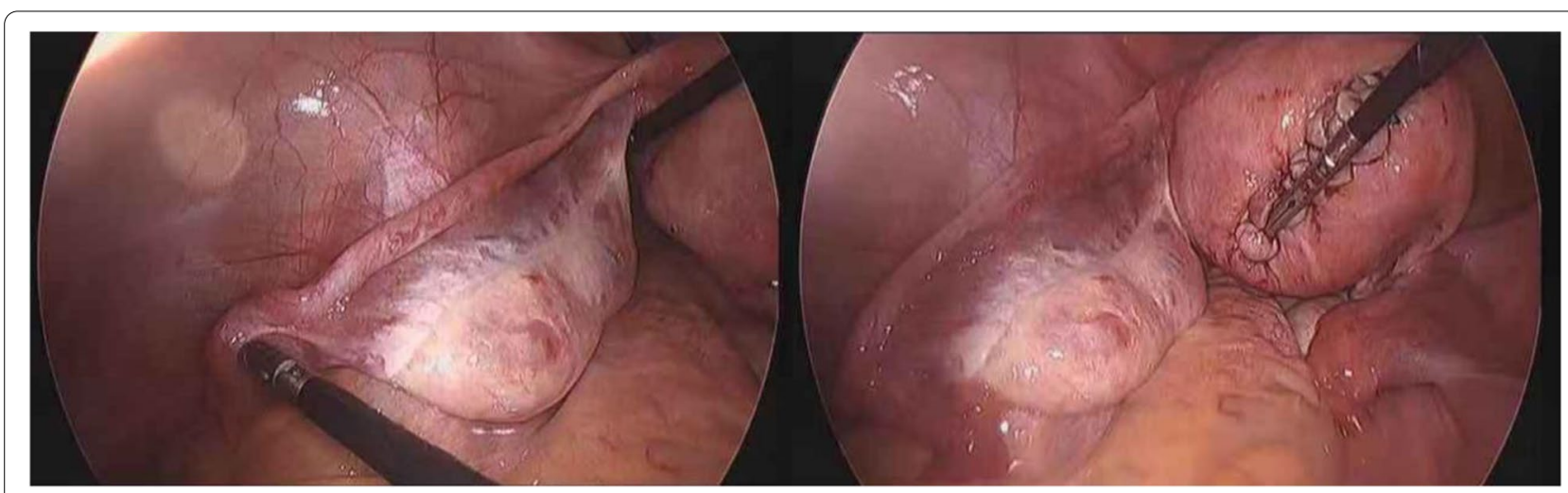

Fig. 5 Laparoscopy image of Case 4: laparoscopy showed left-sided undescended ovary with long fallopian tube 
Table 1 The summary of diagnosis and treatment of patients

\begin{tabular}{|c|c|c|c|c|c|c|c|c|}
\hline Case \# & Age(year) & Disease & $\begin{array}{l}\text { Duration of } \\
\text { infertility(years) }\end{array}$ & $\begin{array}{l}\text { Operation } \\
\text { time (month, } \\
\text { year) }\end{array}$ & $\begin{array}{l}\text { Complicated } \\
\text { with Mullerian } \\
\text { duct } \\
\text { malformation }\end{array}$ & $\begin{array}{l}\text { Other factors } \\
\text { of infertility }\end{array}$ & $\begin{array}{l}\text { Affected side } \\
\text { of the ovary }\end{array}$ & $\begin{array}{l}\text { Pregnancy } \\
\text { outcome }\end{array}$ \\
\hline 1 & 21 & Primary infertility & 3 & July, 2016 & No & No & Double & N/A \\
\hline 2 & 34 & Primary infertility & 1 & January, 2018 & No & No & Double & $\begin{array}{l}\text { Patient was con- } \\
\text { ceived naturally } \\
\text { after operation }\end{array}$ \\
\hline 3 & 28 & Ectopic pregnancy & 0 & January, 2018 & No & No & Right & $\begin{array}{l}\text { Patient was con- } \\
\text { ceived naturally } \\
\text { after operation }\end{array}$ \\
\hline 4 & 31 & Uterine fibroids & 0 & July, 2019 & No & No & Right & $\begin{array}{l}\text { Patient doesn't } \\
\text { have plan }\end{array}$ \\
\hline
\end{tabular}

around the ovaries, which might be mistaken for distal tubal obstruction. Furthermore, if patients had obesity or intestinal gas, the diagnosis will be more difficult. Compared with contrast-enhanced ultrasound, HSG has an advantage in the diagnosis of undescended ovary. HSG in Case 2 suggested that the fallopian tube on the dysplastic side (right side) was raised, and the right fallopian tube can be found in the X-ray imaging (Figure 4). The contrast medium was concentrated and diffused in the iliac fossa, indicating that the position of the fallopian tube was abnormal, but the lumen was unobstructed.

The mechanism of undescended ovary remains unclear, but previous studies indicated that it might be because of the lack of embryological caudal descent or the incidental growth restriction of a specific portion of the genital ridge [2]. As Mullerian anomalies were previously thought to be a multifactorial process. A review of the literature found that it may be more common in patients with infertility or individuals with abnormal development of the uterine or renal system [10]. The relationship between undescended ovary and infertility is still not clear. However, literature suggested that women with infertility have a high risk in the incidence of undescended ovary, which may be associated with high ovarian position accompanied by extended fallopian tubes correspondingly, and fertilized eggs cannot swim back to the uterine cavity bed on time [11]. There is no evidence that undescended ovary has impaired function, and the ovarian functions of these four patients were still normal. Therefore, patients with undescended ovary combined with infertility may consider IVF/ET for pregnancy [12]. Oocyte retrieval will not cause a difficulty if IVF is contemplated. It can be retrieved through the abdomen and anterior superior iliac spine. Undescended ovary combined the extended fallopian tubes also increase various risk such as ectopic pregnancy [13], ovarian twist, and ovarian tumors [14]. Therefore, the accurate diagnosis of potential risk of infertility for patients are of importance in the treatment of undescended ovary.

\section{Conclusion}

In conclusion, undescended ovary is rare. For ovary examination, if one-sided or tow-sided ovaries with indistinct ovarian borders or small ovaries shrinkage, was found in ultrasound imaging, it indicated the patient might have undescended ovary. If the patient has periodic post-sacral spinal pain, MRI or HSG can be used for diagnosis. Because this phenomenon is rare, it is necessary to communicate with radiologist well, to provide an accuracy of diagnosis. Laparoscopic profiling is the gold standard. Patients with undescended ovary should understand that natural pregnancy is possible, but patients with infertility could consider active IVF-ET for pregnancy.

\section{Acknowledgements}

This work was supported by Shenzhen Science and Technology Innovation Committee Technical Research Project (Grant No. JCYJ20190809144801670 and JSGG20180703164202084) and Shenzhen Sanming Project (SZSM201412010) and Shenzhen High-level Hospital Construction Fund(YBH2019-260).

\section{Authors' contributions}

All authors were involved in drafting the article or revising it, and all authors approved the final version to be published. Conception \& Design of Study: Weixia Wei and Ruifang Wu. Data Collection: Weixia Wei, Wenji L, Qicai Hu, and Liping Zeng. Data Analysis \& Interpretation: Weixia Wei and Wenji Luo. Responsible Surgeon or Imager: Weixia Wei, Wenji Luo, and Liping Zeng. Patient Recruitment: Weixia Wei, Wenji Luo and Qicai Hu. Weixia Wei and Wenji Luo contributed equally to this work.

\section{Funding}

This work was supported by Shenzhen Science and Technology Innovation Committee Technical Research Project (Grant No. JCYJ20190809144801670 and JSGG20180703164202084) and Shenzhen Sanming Project

(SZSM201412010) and Shenzhen High-level Hospital Construction Fund(YBH2019-260). 
Availability of data and materials

Contact author for data requests.

\section{Declarations}

\section{Ethics approval and consent to participate}

The study was approved by the Research Ethics Committee at Peking University Shenzhen Hospital (2020-016).

Informed consent was obtained from all individual participants included in the study.

\section{Consent for publication}

All the authors mutually agree that this manuscript can be published in Journal of Ovarian Research.

\section{Competing interests}

The authors declare no competing interest.

\section{Author details}

${ }^{1}$ Department of Obstetrics and Gynecology, Peking University Shenzhen Hospital, Shenzhen 518020, Guangdong Province, China. ${ }^{2}$ Shenzhen Key Laboratory on Technology for Early Diagnosis of Major Gynecologic Diseases, Shenzhen ,518036, China.

Received: 11 August 2020 Accepted: 22 September 2021

Published online: 22 November 2021

\section{References}

1. Verkauf BS, Bernhisel MA. Ovarian maldescent. Fertil Steril. 1996;65(1):189-92.

2. Dietrich JE, Hertweck SP, Bond S. Undescended ovaries: a clinical review. J Pediatr Adolesce Gynecol. 2007;20(2):57-60.

3. Ireo E, Haruna M, Gandhi P. Laparoscopic management of maldescended ovary presenting with recurrent acute abdomen. Gynecol Minim Invasive Ther. 2018;7(2):74
4. Allen JW, Cardall S, Kittijarukhajorn M, Siegel CL. Incidence of ovarian maldescent in women with müllerian duct anomalies: evaluation by MRI. Am J Roentgenol. 2012;198(4):W381-W5.

5. Garg D, Grazi R, Kankanala N, Melzer-Ross K. Bilateral ovarian maldescent: Unusual cause of infertility-A case report and literature review. J Obstet Gynaecol Res. 2016;42(8):1038-41

6. Exacoustos C, Di Giovanni A, Szabolcs B, Binder-Reisinger H, Gabardi C, Arduini D. Automated sonographic tubal patency evaluation with three-dimensional coded contrast imaging (CCI) during hysterosalpingo-contrast sonography (HyCoSy). Ultrasound Obstet Gynecol. 2009;34(5):609-12.

7. Cheng Q, Wang S-S, Zhu X-S, Li F. Evaluation of tubal patency with transvaginal three-dimensional hysterosalpingo-contrast sonography. Chin Med Sci J. 2015:30(2):70-5.

8. Alcázar JL, Corral TM-A, Orozco R, Dominguez-Piriz J, Juez L, Errasti T. Three-dimensional hysterosalpingo-contrast-sonography for the assessment of tubal patency in women with infertility: a systematic review with meta-analysis. Gynecol Obstet Investig. 2016;81(4):289-95.

9. Rajesh H, Lim SL, Yu SL. Hysterosalpingo-foam sonography: patient selection and perspectives. Intern J Womens Health. 2017;9:23.

10. Hur C, Rehmer J, Flyckt R, Falcone T. Uterine factor infertility: a clinical review. Clin Obstet Gynecol. 2019;62(2):257-70.

11. Sinonquel P, Bontinck J, Stevens M. Undescended ovary and fallopian tube presenting as appendiceal mucocele. Facts Views Vis Obgyn. 2018:10(1):47.

12. Van Voorhis BJ, Dokras A, Syrop CH. Bilateral undescended ovaries: association with infertility and treatment with IVF. Fertil Steril. 2000;74(5):1041-3.

13. Kives SL, Perlman S, Bond S. Ruptured hemorrhagic cyst in an undescended ovary. J Pediatric Surg. 2004;39(11):e4-6.

14. Seyam E, Hefzy E. Evaluation of the correlation between insulin like factor 3, polycystic ovary syndrome, and ovarian maldescent. Gynecol Endocrinol. 2018;34(6):481-8.

\section{Publisher's Note}

Springer Nature remains neutral with regard to jurisdictional claims in published maps and institutional affiliations.
Ready to submit your research? Choose BMC and benefit from

- fast, convenient online submission

- thorough peer review by experienced researchers in your field

- rapid publication on acceptance

- support for research data, including large and complex data types

- gold Open Access which fosters wider collaboration and increased citations

- maximum visibility for your research: over 100M website views per year

At BMC, research is always in progress.

Learn more biomedcentral.com/submissions 